\title{
Obstructive Uropathy in Children - An Update
}

\author{
RANJIT RANJAN ROY ${ }^{1}$, MD FIROZANJUM ${ }^{2}$, SHAHANA FERDOUS ${ }^{3}$
}

\begin{abstract}
:
Obstructive nephropathy is a structural or functional hindrance of normal urine flow, sometimes leading to renal dysfunction. Urinary tract obstruction can result from congenital (anatomic) lesion or can be caused by trauma, neoplasia, calculi, inflammation or surgical procedures, although most childhood obstructive lesions are congenital. The clinical features in most of the patients are due to consequences of the obstruction ${ }^{2}$. Obstruction of the urinary tract generally causeshydronephrosis, which is typically asymptomatic in its early phase. Renal USG gives information about urinary tract dilatation, renal cortical thickness, calyx size, diameter of pelvis, ureter, bladder thickness, tumor \& calculi and doppler USG for evaluation of aberrentvessles. Once obstructive nephropathy has been identified therapy focuses on the rapid restoration of normal urine flow either by medical or surgical intervention.
\end{abstract}

Key words: Obstructive Uropathy, Posterior urethral valve, pyelonephritis, IVU, MCU

\section{Introduction:}

Urinary tract obstruction refers to as restriction to the urinary outflow that if not managed satisfactorily, leads to progressive renal damage. Obstructive uropathy is an important cause of end stage renal disease requiring renal replacement therapy. ${ }^{1}$ The kidney is an indispensable organ for maintaining homeostasis. The renal system plays diverse role including hormonogenesis, metabolism, detoxification \& excretion of urine which contains agents that may be injurious to the body. The ability of the kidneys to excrete unwanted products of metabolism depends on adequate flow through the urinary tract. ${ }^{2}$ Urinary tract obstruction initiates a complex sequence of events resulting in impaired renal function \& obstructive nephropathy is a major cause of renal impairment in infants \& children. ${ }^{3}$

Obstruction of the urinary tract generally causes hydronephrosis. Antenatal ultrasonography detects hydronephrosis in about 1 in 100 fetuses, the prevalence ranging from 0.6 to 5.4 percent depending on diagnostic criteria. The condition is bilateral in 17 to 54 percent and additional abnormalities are occasionally associated. In early development, chronic

1. Professor, Department of Paediatric Nephrology, BSMMU, Dhaka

2. MD (Phase-B Resident), Department of Paediatric Nephrology, BSMMU, Dhaka

3. Consultant, Department of Paediatric Gastroenterology, Impulse Hospital, Nakhalpara, Dhaka

Received: 23 February, $2017 \quad$ Accepted: 17 June, 2017 urinary tract obstruction impairs renal growth \& development. ${ }^{1}$ The approach to obstructive nephropathy should be to detect site of obstruction, to find out whether obstruction is complete or partial, unilateral or bilateral, to findthe cause of obstruction and to decide need forsurgery and to plan the medical treatment. ${ }^{4}$

\section{Etiology:}

Urinary tract obstruction can result from congenital (anatomic) lesion or can be caused by acquired such as trauma, neoplasia, calculi, inflammation or surgical procedures ${ }^{5}$, although most childhood obstructive lesions are congenital. ${ }^{6}$ Obstructive lesion can occur at any point from the calyces to the tip of urethra. ${ }^{7}$ Ureter can be obstructed by external compression or kinks at any site along its course in the retroperitoneum. It is anatomically narrow at the pelviureteric\&uterovesical junction \& where it crosses the iliac artery. Similarly the urethra is vulnerable to obstructive pathology at the internal and external meatus. The common causes of obstruction are listed below : $1,4,5$

- Calyx: Infundibular stenosis, Tuberculosis, Calculi.

- Pelviureteric junction: Intrinsic abnormalities, Congenitalpelviureteric junction obstruction, Kinks, Bands, Adhesion, Calculi, Aberrent vessels.

- Ureter: Stricture, Calculi, Vascular obstruction, Ureterocele, Primary megaureter. 
- Ureterovesical junction obstruction: Ureterocele, Congenital obstruction.

- Bladder: Diverticulum, Bladder neck hypertrophy, Calculi, Neuropathic bladder.

- Posterior urethra: Posterior urethral valve, Diverticulum, Stricture, Polyps.

- Anterior urethra: Diverticulum, Stricture, Valves, Polyps.

- Meatus : Stenosis, Phimosis, Prepucial adhesion.

\section{Pathophysiology:}

The effects of obstruction anywhere in the urinary tract are predictable. Obstruction in the urethra, the most distal part of urinary tract, results in dilatation of the proximal urethra. ${ }^{1}$ The bladder in an attempt to overcome the obstruction undergoes hypertrophy manifested by thickening of bladder wall, trabeculation, sacculation and hypertrophy of bladder neck. The intravesical pressure increases causing decreased emptying of ureter into bladder and reflux of urine into the ureter. The resultant effect is dilatation of ureter, which also undergoes hypertrophy. 1,4,5 The intraureteric pressure rises $\&$ back pressure lead to hydronephrosis and thinning of renal parenchyma. Stasis of urine in the dilated tract results in repeated infections. ${ }^{1,4,5}$ The combination of stasis, repeated infections and high intraluminal pressure results in renal parenchymal scarring and progressive chronic kidney disease, suggested by proteinuria and hypertension. The resulting impairment of renal function is detrimental to normal growth and development, and may be life threatening. 1,4,5

In acute obstruction (e.g from a calculus) glomerular filtration ceases and tubular transport is markedly reduced. ${ }^{6}$ If obstruction becomes more prolonged, renal fibrosis and permanent damage ensues. Obstruction during the intrauterine period is more serious and leads to renal dysplasia of varying severity. $1,4,5$ Postnatally even if the obstruction is releived, renal damage is irreversible and may progress to end stage renal disease (ESRD) at an early age..$^{1,4,5}$

\section{Clinical Manifestations:}

The clinical feature in most of the patient are due to consequences of the obstruction. ${ }^{2}$ Obstruction of the urinary tract generally causes hydronephrosis, which is typically asymptomatic in its early phase. ${ }^{5} \mathrm{An}$ obstructed kidney secondary to aureteropelvic junction or ureterovesical junction obstruction can manifest as mass or cause upper abdominal or flank pain on affected side. ${ }^{1,4,5}$ Pyelonephritis can occur because of urinary stasis. ${ }^{1,5,7}$ An upper urinary tract stone can cause abdominal or flank pain and hematuria. With bladder outlet obstruction, the urinary stream may be weak, dribbling of urine, straining, retention and palpable bladder; urinary tract infection is common. ${ }^{1,4,5}$ An acute obstruction may cause flank pain, nausea, vomiting. Chronic obstruction can be silent or can cause vague abdominal pain with increased fluid intake. In young infant features of sepsis may be there due to pyelonephritis. ${ }^{1}$ Obstructive renal insufficiency can manifest itself by failure to thrive, vomiting, diarrhoea or other non-specific signs and symptoms. ${ }^{5}$

\section{Investigations:}

Imaging and radionuclide procedures are necessary to evaluate for obstructive uropathy. These include ultrasongraphy, radiocontrast studies, magnetic resonance (MR) imaging and MR urography and radionuclide scintigraphy. Endoscopy can be diagnostic as well therapeutic in some situations (e.g., posterior urethral valce). ${ }^{1}$ The indications and role of various imaging modalities are summarized in Table-I.

The application of routine antenatal ultrasonography has advanced the understanding and recognition of obstructive uropathy in early infancy. It allows prompt investigation and appropriate management in the neonatal period. Antenatal hydronephrosis which is graded by the trimester and the anterior-posterior diameter of the renal pelvis Table-II. Although most pediatric urologists grade the severity of the hydronephrosis from 1-4 using the society of fetal urology (SFU) grading scale Table-III, whereas pediatric radiologists generally utilize the adjectives mild, moderate and severe. ${ }^{1,5}$

Although ultrasonography detects dilatation, it provides little information about the functional status of the kidney. A radionuclide dynamic renogram (withdiethylenetriaminepentaacetic acid, DTPA or ${ }^{99 m}$ Tc-L, L-ethylenedicysteine, LLEC) is necessary for evaluating obstruction and determining individual renal function. A glomerular agent provides information about GFR and renal tracer uptake, whereas a glomerular / tubular agent about the renal uptake , split renal function and pattern of drainage pattern. Theintravenous urogram (IVU), although providing superior anatomic details, is carried out if facilities for radionuclide scintigraphy are not available. ${ }^{1}$ 
Table-I

Modalities for evaluation of obstructive uropathy ${ }^{1}$

Ultrasonography: Urinary tract dilation, renal cortical thickness, calyceal size, pelvic anteroposterior diameter, ureter dilation, thickness of bladder, mass, claculi

Doppler ultrasound: Renal blood flow, abberrent vessels, resistive index

Radiocontrast studies:

Intravenous pylography (IVP): Hydrocalyx, hydronephrosis, calculi, ureterocele

Micturationcystourethrography (MCU): Bladder and urethral obstruction, vesicoureteric reflux (VUR)

Retrograde urethrography: Urethral obstruction

Retrograde, antegradeureteropyelography: Ureteral and pelviureteric junction obstruction

Computed Tomography (CT), Magnetic Resonance Imaging (MRI) Scan: Complex congenital anomalies, duplex system, pooly functioning kidney

Radionuclide studies:

DTPA, LLEC Scan: Upper tract function, obstruction, split renal function, GFR

Dimercaptosuccinic acid (DMSA), Mercaptoacetyltriglycine (MAG3) Scan: Renal scaring

Radionuclide cystogram: Vesicoureteric reflux, bladder outlet obstruction

Endoscopy: Direct visiualization (e.g., posterior urethral valve), therapy (valves, ureterocoele)

Table-II

Definition of Antenatal Hydronephrosis by Anteriorposterior pelvic Diameter ${ }^{1}$

\begin{tabular}{lll}
\hline $\begin{array}{l}\text { Grade of } \\
\text { hydronephrosis }\end{array}$ & $\begin{array}{l}\text { Second } \\
\text { trimester }\end{array}$ & $\begin{array}{l}\text { Third } \\
\text { trimester }\end{array}$ \\
\hline Mild & 4 to $<7 \mathrm{~mm}$ & 7 to $<9 \mathrm{~mm}$ \\
Moderate & 7 to $\leq 10 \mathrm{~mm}$ & 9 to $\leq 15 \mathrm{~mm}$ \\
Severe & $<10 \mathrm{~mm}$ & $<15 \mathrm{~mm}$ \\
\hline
\end{tabular}

Table-III

Society of fetal urology grading for hydronephrosis ${ }^{1}$

\begin{tabular}{|c|c|c|}
\hline Grade & Renal pelvis & $\begin{array}{l}\text { Parenchymal } \\
\text { thickness }\end{array}$ \\
\hline$\overline{0}$ & Intact: no splitting & Normal \\
\hline 1 & Mild splitting & Normal \\
\hline 2 & $\begin{array}{l}\text { Moderate splitting } \\
\text { (confined to renal border) }\end{array}$ & Normal \\
\hline 3 & $\begin{array}{l}\text { Marked } \\
\text { (outside renal border, } \\
\text { calyceal dilatation) }\end{array}$ & Normal \\
\hline 4 & Pelvicalyceal dilatation & Thin \\
\hline
\end{tabular}

\section{Posterior Urethral Valve:}

The most common cause of childhood obstructive uropathy is posterior urethral valve (PUV) leading to renal failure. ${ }^{7}$ The estimated incidence of $4 / 10,000$ births ${ }^{1}$. Approximately $5-64 \%$ of these patient experience ESRD during childhood or adolescence. ${ }^{8}$ Valves are tissue leaflets fanning distally from the prostatic urethra to the external urinary sphincter ${ }^{5}$. Posterior urethral valves (PUV) are of 3 types. Type-I commonest from, appear to radiate distally from the verumontanum\& merge into each other to form anterior commisure. Type-Il usually undetected because the valves spread proximally and do not obstruct the flow of urine. Type-III are less common, consisting of a diaphragm with a central hole, and the diagnosis is confirmed by MCU ${ }^{1}$ (figure-1). PUV begins to show effects on the developing urinary tract early in second trimaster of development, the back pressure produced by the valves may results in vesicoureteric reflux (VUR), hydronephrosis, renal dysplasia \& impaired renal function ${ }^{9}$. VUR occurs in $50 \%$ of patents. ${ }^{5}$ The children often present in the antenatal phase based on antenatal ultrasound scans. The classical features on antenatal scanning include oligohydramnios, bilateral hydronephrosis \& hydroureter, a thick-walled bladder and a dilated posterior urethra, renal dysplasia and pulmonary hypoplasia. ${ }^{10}$ Attempts at antenatal treatment have been made to treat a fetus with PUV because renal dysplasia associated with PUV is not reversible. Fetal urine biochemistry suggesting satisfactory renal function are sodium $<100 \mathrm{mEq} / \mathrm{l}$, chloride $<90 \mathrm{mEq} / \mathrm{l}$, osmolality below $210 \mathrm{mosm} / \mathrm{L}$, 
urine output $>2 \mathrm{ml} /$ hour and beta- 2 microglobulin Â6 $\mathrm{mg} / \mathrm{L} .{ }^{1}$ Vesicoamniotic shunt has been described to overcome such poor prognosis to gain time for prolonging the pregnancy and protecting the developing kidneys \& lungs. ${ }^{11}$ Postnatally surgical ablation of the valve is carried out after treating any associated urinary tract infection(UTI) and correction of fluid and electrolyte abnormality. High urinary diversion such a high loop ureterostomy is considered if the child is too sick, has gross pyuria\& if the trial of bladder drainage has not helped. ${ }^{9}$


Figure-1.

\section{Pelviureteric Junction Obstruction:}

Pelviureteric junction (PUJ) obstruction is due to functional obstruction of junction between the renal pelvis and ureter. ${ }^{10}$ It is the most common cause of hydronephrosis with an incidence of 1 in 2000 children, ${ }^{12}$ with a male female ratio $3: 1$ \& bilateral in $20-25 \%$ of cases. ${ }^{13}$ This could be due to intrinsic abnormality, muscular abnormalities of the ureter, ureteral polyps, ureteral folds, crossing vessels \& rarely secondary to VUR. ${ }^{1,11}$ Children may present with abdominal pain (dull constant pain or severe spasmodic pain), lump or UTI. Gross hematuria may occur following minor abdominal trauma. Pain and abdominal mass that resolves with passage of a large amount of urine (Dielt's crisis) are uncommon. ${ }^{1,9}$ The obstruction is generally suspected antenatally in a fetus with hydronephrosis without ureteric dilatation and with a normal bladder and normal amniotic fluid volume. ${ }^{10}$ Postnatally the majority of mild to moderate PUJ obstruction will tend to deteriorate within the first 6 months of life as a result of maturational changes in
GFR. ${ }^{9}$ The diagnosis of PUJ obstruction is established by ultrasonography and dynamic renal scintigraphy (diethylenetriaminepentaacitic acid, DTPA). ${ }^{1,10} \mathrm{MCU}$ is also necessary because $10-15 \%$ of patients have ipsilateral VUR. If the kidney shows grade 1 or 2 hydronephrosis and the renal parenchyma appears normal a period of observation is usually appropriate and antibiotic prophylaxis not indicated. If the hydronephrosis is grade 3 or 4 , diameter of renal pelvis more than $3 \mathrm{~cm}$, poor upper urinary tract drainage or poor differential renal function after diuretic renogram then surgery, Anderson Hynes pyeloplasty is recommended. ${ }^{5}$

\section{Vesicoureteric Reflux (VUR):}

VUR refers to the retrograde flow of urine from the bladder to the ureter and kidney. The ureteral attachment to the bladder normally is oblique, between the bladder mucosa and detrusor muscle, creating a flap valve mechanism that prevent reflux. Reflux occurs when the submucosal tunnel between the mucosa and detrusor muscle is short or absent. ${ }^{13}$ It is detected in as many as $38 \%$ of children with prenatal hydronephrosis. ${ }^{14}$ VUR is unusual in normal children. In term or preterm neonates its incidence is $0.4 \%$. Twenty to thirty percent of children and $40-50 \%$ of neonates with UTI have VUR. $20-40 \%$ of children with UTI and VUR develop renal scarring, of which 5-10\% progress to ESRD. Gross VUR during infancy is mostly seen in boys and is usually bilateral. In older children, girls are often affected and have milder VUR ${ }^{1}$. Reflux is present at birth in $25 \%$ of children with neuropothic bladder, $50 \%$ of boys with PUV, $15 \%$ with multicystic dysplastic kidney or renal agenesis, PUJ obstruction. ${ }^{1,7}$

Reflux predisposes to renal infection (pyelonephritis) by facilitating the transport of bacteria from the bladder to the upper urinary tract. The intrarenal reflux, bacterial virulence and the host inflammatory response may result in renal injury or scarring, renal insufficiency, ESRD. ${ }^{1,15}$ Reflux severity is graded using the international reflux study classification is based on the appearance of the urinary tract on a contrast voiding cystourethrogram (VCUG). ${ }^{5}$ GradeI: reflux into a nondilated ureter: Grade-II: reflux into the upper collecting system without dilatation, GradeIII: reflux into dilated ureter and blunting of calycealfornices ; Grade-IV: reflux in to a grossly dilated ureter; Grade V : massive reflux with significant ureteral dilatation andtortuority\& loss of 
the papillary impression ${ }^{16}$ (figure-2). The objective of treatment are to prevent pyelonephritis, reflux related renal injury and other complications of reflux.Grades 1-2, antibiotics prophylaxis until 1 year old and restart antibiotic prophylaxis after treatment of breakthrough febrile UTI. Grades 3-5, antibiotic prophylaxis until 5 years old, consider surgery if breakthrough febrile UTI; beyond 5 years, prophylaxis continued if there is bowel bladder dysfunction ${ }^{1}$. Surgical reimplantation and endoscopicsubmucosal injection of deflux in intramural segment of ureter for grade IV, V are modalities of treatment. ${ }^{1,17}$

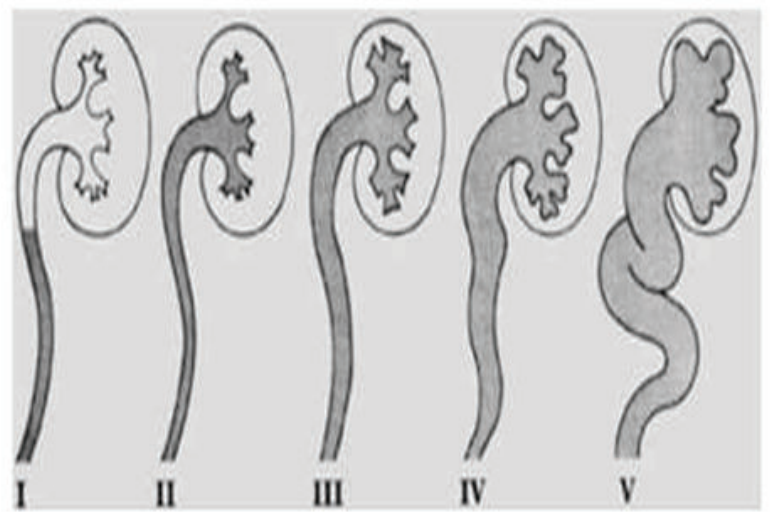

Fig.-2

\section{Neurogenic Bladder:}

Neurogenic bladder refers to dysfunction of the urinary bladder due to disease of the central nervous system or peripheral nerves in the control of micturition. ${ }^{18}$ The child who presents mainly with incontinence it is important to exclude a neuropathic bladder. The causes are numerous including dysraphism, open and closed spina bifida, sacral agenesis, spinal cord tumor, trauma, transverse myelitis and autonomic neuropathy. ${ }^{19}$ Worrying features in the clinical assessment that might lead one to suspect a neuropathic bladder are poor or impaired urinary stream, straining to pass urine, impaired / lack of bladder sensation, small urinary volumes, continual dribbling, infrequent micturition, impaired bladder emptying, recurrent UTI, abnormality of the spine, abnormality of lower limb \& associated constipation. ${ }^{18,19}$ For diagnosis USG of abdomen is carried out to determine kidney size, urinary bladder capacity, wall thickness upper tract dilatation. AMCU is done to look for VUR and dimercaptosuccinic acid ( ${ }^{99 m}$ TC DMSA) scintigraphy for renal scars. A urodynamic study should be promptly carried out, procedure that looks at how well the bladder sphincter and urethra are storing and releasing urine. ${ }^{20}$ The Management aims are to preserve renal function and improve continence. Non surgical management includes supra pubic massage (the credemanoeuvre), bladder straining, clean intermittent catheterization (CIC), anticholinergic drugs. Surgery like vesicostomy, bladder augmentation, urinary diversion, sphincterotomy, reimplantation of ureters are recommended $^{19}$. In children with difficulty in catheterization a Mitrofanoff conduit using the appendix is created to enable catheterization through a stoma on the abdominal wall. ${ }^{20}$

\section{Urolithiasis:}

There is a wide geogrophical variation in the incidence of lithiasis in childhood. Approximately $7 \%$ of urinary calculi occur in children less than 16 years of age. ${ }^{21}$ Many children with stone disease have a metabolic abnormality ${ }^{22}$. Nearly $90 \%$ of urinary stones contain calcium as a major constituent, and $60 \%$ are composed of calcium oxalate. Most "spontaneous" stones are composed of calcium, oxalate, or phosphate crystals; others are caused by uric acid, cystine, ammonium crystals, or phosphate crystals, or a combination of these substances. The risk of stone formation increases in the presence of increasing concentrations of these crystals and is reduced with increasing concentrations of urinary inhibitors. Associated common conditions are hypercalciuria, hyperoxaleuria, hyperuricosuria, UTI, cysteinuria and urinary tract anomalies. ${ }^{21}$ The usual symptoms are recurrent flant pain, renal colic, repeated attacks of urinarytract infections and gross or microscopic hematuria. Pain is a common symptom in adolescents and school aged children, but present in only one half of children below 6 years of age. The child may pass gravel or a small stone. A stone in the urethra or in both ureters may rarely precipitate acute renal failure. ${ }^{23}$ Laboratory investigations suggested are imaging such as plain x-ray, USG, CT scan of abdomen, IVP, blood for urea, creatinine, electrolyte, $\mathrm{pH}$, calcium, phosphate, alkaline phosphatase, parathyroid hormone, uric acid \& urine for routine microscopic examination and culture sensitivity, spot urinary calcium, uric acid, oxalate, citrate and 24 hour calcium creatinine ratio $\&$ other ratios and stone analysis ${ }^{23}$. Specific medical management such as thiazides for hypercalciuria, alkali administration in renal tubular acidosis, 
allopurinol in hyperuricosuria and some surgical measure like extracorporeal shock wave lithotripsy, percutaneous nephrolithotomy or open surgery are also done. ${ }^{23}$

\section{Urethral Stricture:}

Urethral stricture usually common in boys. It can be congenital or acquired. Congenital stricture urethra are not common \& are usually located in membranous urethra. Acquired stricture may be due to infection, trauma either iatrogenic (catheterization, endoscopic procedures, previous urethralreconstruction) or accidental (straddle injuries, pelvic fractures). ${ }^{5}$ Child may present with dribbling of urine or thin urinary stream associated with straining, hematuria, dysuria, palpable bladder and occasionally palpable kidneys. There may be inability to catheterize the bladder. ${ }^{1}$ The diagnosis is made by a voiding film obtained during intravenous urography (IVU) or retrograde urethrography. Ultrasonogtaphy also has been used to diagnose, endoscopy in confirmatory ${ }^{5}$. Surgery in the mainstray of treatment which includes urethrotomy, urethral dilatation, urothroplasty. ${ }^{2,3}$

\section{Phimosis:}

Phimosis refers to the inability to retract the prepuce. At birth phimosis is physiologic. Over time the adhesions between the prepuce, glans lyse \& the distal phimotic ring loosens. ${ }^{24}$ At the end of the first year of life retraction of foreskin behind the glandular sulcus is possible in only about $50 \%$ of boys, this rises to approximately $90 \%$ by the age of 3 years. ${ }^{1,25}$ In true phimosis predispose to smegma collection which may cause recurrent balanoprosthitis. ${ }^{1,26}$ If physiological phimosis is not resolved by 3 years of age $\&$ child has history of dysuria then treatment with corticosteroid cream is preferred. ${ }^{1,27}$ Circumcission is required in true phimosis.

\section{Hydronephrosis:}

Hydronephrosis is defined as dilatation of the renal pelvis and or calices is detected by routine prenatal USG with an incidence of 0.5 to $1 \%$ and is most frequently detected prenatal anomaly. ${ }^{26}$ The majority are detected between 18 and 20 weeks of gestation at the routine anomaly scan. ${ }^{13}$ The severity of hydonephrosis is graded on the degree of renal anteroposterior pelvis diameter (APD) (Table-2 and 3). ${ }^{27}$ APD greater than $5 \mathrm{~mm}$ is considered abormal ${ }^{13}$. Hydronephrosis is unilateral but may be bilateral in $15-30 \%$ cases $^{28}$. Society of fetal urology grading of hydronephrosis. ${ }^{5}$ Obstruction in case of bilateral hydronephrosis with increasing oligohydramnios, by placing a vesicocamniotic shunt. ${ }^{27}$ Antibiotic prophylaxis has been recommended empirically in patient with fetal hydronephrosis ${ }^{15}$. Postnatally USG is done during first week of life. If USG reveals no abnormalities then follow up USG done 3-4 months later. If USG reveals hydronephrosis, evaluation of VUR \& antibiotic prophylaxis recommended. MCU, diuretic renography done at 4-6 weeks of age \& subsequently managed according to etiology. Surgery is required in $28 \%$ cases. PUV account for $1-4 \%$ and the only definite indication for surgery. ${ }^{27}$

\section{Megaureter}

Megaureters are dilated ureters with a luminal diameter of $8 \mathrm{~mm}$ or more. The condition s bilateral in $25 \%$ and the contralateral kidney is absent or dysplastic in 10$15 \%$. Primary megaureter is considered to be due to an aperistaltic (adynamic) juxtavesical segment. Megaureter can also be classified as obstructed, refluxing, obstructed and refluxing or neither obstructing nor refluxing. Secondary obstructive megaureter represents an obstructive process due to elevated bladder pressure. Common causes include spina bifida, tethered spinal cord and neurogenic bladder. Other anatomic cause of secondary distal urethral obstruction includeureterocele, ectopic ureter, bladder diverticula, periuretral fibrosis and external compression by retroperitoneal tumor, masses or aberrant vessels. Feature include UTI, groin pain and occasionally hematuria. Diagnosis is done by DTPA renogram and $\mathrm{MCU}$; urography may be necessary. Treatment is surgical obstructed ureter and reimplantation. Nephroureterectomy is necessary if he split renal function of the same side is poor $(>5-10 \%){ }^{1}$

\section{Complications:}

Congenital obstructive nephropathy is the most common cause of chronic kidney disease (CKD) and ESRD in children ${ }^{1}$. Symptomatic and asymptomatic UTI both are common. The stretch injury leads to bladder dysfunction. Hypertension is common in presence of scarred kidney as well as proteinuria. Urinary stone commonly form in infected urine. Often fluid and electrolyte abnormalities, systemic acidosis (distal RTA) occur due to inadequate urinary acidification. ${ }^{29}$ Growth retardation due to bony abnormalities and failure to thrive are also observed. ${ }^{1,30}$ 


\section{Treatment}

Once obstructive nephropathy has been identified therapy focuses on the rapid restoration of normal urine flow either by medical or surgical intervations. Treatment of any accompanying infection mainly UTI with antibiotics and management of post obstructive complications. Initially patient may require acute renal replacement therapy to remove toxins and maintain fluid, electrolyte \& acid base balance until adequate renal function returns ${ }^{25}$. Some patient may experience enough recovery of renal function and compensatory function of the remaining nephrons to come off dialysis once established. ${ }^{11}$

In patients with CKD electrolyte abnormalities are common mostly hyperkalemia and hyperphosphatemia. Low potassium, low phosphorus diets may be necessary in addition to dietary phosphate binders. ${ }^{11}$ Anemia is corrected with iron supplementation or human recombinant erythropoietin. There is also reduced production of 1,25-dihydroxy vitaminD, necessitating supplementation. Growth failure is another common problem require nutritional supplementation and recombinant growth hormone. ${ }^{31}$

\section{Prognosis :}

$16.3 \%$ of pediatric obstructive nephropathy patient goes into ESRD requiring renal transplantations. ${ }^{32}$ Long term renal function is variable in patients depending on how long it takes for nephropathy, underlying pathology, the presence or absence of UTI and the degree of obstruction. Prognosis is worse if UTI remains untreated. ${ }^{19}$ Earlier diagnosis by pediatrician and skilled intervention by pediatric urologist can give rise better outcome.

\section{References:}

1. Bhatnagar V, Srinivas M. Obstructive Uropathy. In: Srivastava RN, Bagga A (eds.), Pediatric Nephrology. $6^{\text {th }}$ ed. New Delhi: Jaypee Brothers Medical Publishers (p) Ltd.; 2016. p. 476-489.

2. Eke N, Elenwo SN. Obstructive uropathy in childhood: A Review, Port Harcourt medical Journal 2007; 1:137-44.

3. Chevalier RL, Peters CA. Obstructive uropathy. In: Avner ED, Harmon WE, Niaudret R, Yoshikawa $\mathrm{N}$ (editors), Pediatric Nephrology. $7^{\text {th }}$ ed. Berlin Heidelberg: Springer-Verlag; 2009. p. 1337-76

4. Mehta K. Approach to obstructive uropathy. Pediatric Oncall. 2000; 1-12.
5. Elder JS. Obstruction of the urinary tract. In: Kliegman RM, Stanton BF, Schor NF, St Geme JW, Behrman RE editors. Nelson textbook of Pediatrics. 20 $0^{\text {th }}$ ed. New Delhi: Elsevier; 2016. p. 2567-75.

6. Zeidel ML. Obstructive Uropathy, Renal and Urology. 2008; 776-80.

7. Woolf AS, Triruchelvam N. Congenital obstructive uropathy: Its origin and contribution to end stage renal disease in children. Adv Ren Replace Ther. 2001;8:157-63

8. Roth KS, Carter WH, Chan JC. Obstructive nephropathy in children: Long term prognosis after relief of posterior urethral valve. Pediatrics 2001;107:1004

9. Postlethwaite RJ, Dickson A. Common urological problems,. In: Nicholas JA, Robert JP (eds.) Clinical Pediatric Nephrology. $3^{\text {rd }}$ ed. New York: Oxford University press; 2003. p. 227-58.

10. Becker A, Baum M. Obstructive uropathy. Science direct 2006; 82:15-22.

11. Makino $\mathrm{Y}$, Kobayashi H, Kyono K, Oshima K, Kawanabayashi J. Clinical results of fetal obstructive uropathy treated by vesicoamniotic shunting. Pediatric Urology 1999.

12. Woodward M, Frank D. Postnatal management of antenatal hydronephrosis. BJU Int. 2002; 89: 149-256.

13. Elder JS. Vesicoureteral reflux. In: Kliegman RM, Stanton BF, Schor NF, St Geme JW, Behrman RE (eds.), Nelson textbook of Pediatrics. $20^{\text {th }}$ ed. New Delhi: Elsevier; 2016. p. 2562-67.

14. Jerin JM, Ritchey ML, Chang AC. Incidental vesicoureteral reflux in neonate with antenatally detected hydronephrosis and other renal abnormalities. Radiology 1993;187:157-60.

15. Woodward M, Frank D. Antenatal renal problems: management in postnatal period. In: Nicholas JA, Robert JP (eds.). Clinical Pediatric Nephrology. $3^{\text {rd }}$ ed. New York: Oxford University press; 2003. p. 269-86

16. Lebowitz RL, Olbing H, Parkkulainen KV, Smelli JM, Tamminen TE. International system of radiographic grading of vesicoureteral reflux. International reflux study in children.Ped Radiol. 1985;15:105-5. 
17. Hari P, Srivastav RN. Obstructive Uropathy. In: Srivastava RN, Bagga A (eds.), Pediatric Nephrology. $6^{\text {th }}$ ed. New Delhi: Jaypee Brothers Medical Publishers (p) Ltd.; 2016. p. 267-89.

18. Elder JS. Enuresis and Voiding dysfunction. In: Kliegman RM, Stanton BF, Schor NF, St Geme JW, Behrman RE (eds.), Nelson textbook of Pediatrics. 20 th ed. New Delhi: Elsevier; 2016. p. 2581-86.

19. Borzyskowski M. Neuropathic bladder: Identification, investigation and management. In: Nicholas JA, Robert (eds.), Clinical Pediatric Nephrology. $3^{\text {rd }}$ ed. New York: Oxford University press; 2003. p. 179-95.

20. Kanitkar M. Disorders of Micturation. In: Srivastava RN, Bagga A (eds.). Pediatric Nephrology. $6^{\text {th }}$ ed. New Delhi: Jaypee Brothers Medical Publishers (p) Ltd.; 2016. p. 503-27.

21. Elder JS. Urinary Lithiasis. In: Kliegman RM, Stanton BF, Schor NF, St Geme JW, Behrman RE (eds.). Nelson textbook of Pediatrics. $20^{\text {th }}$ ed. New Delhi: Elsevier; 2016. p. 2600-04.

22. Leeners B, Sauer J, Schefels J, Cotarelo CL, Funk A. Prune belly syndrome: Therapeutic option including in utero placement of a vesicoamniotic shunt. J Clin Ultrasound 2000; 28: 500-507.

23. Bagga A. Urolithiasis. In: Srivastava RN, Bagga A (eds.). Pediatric Nephrology. $6^{\text {th }}$ ed. New Delhi:
Jaypee Brothers Medical Publishers ( $p$ ) Ltd.; 2016. p. 490-502.

24. Elder JS. Anomalies of the penis and urethra. In: Kliegman RM, Stanton BF, Schor NF, St Geme JW, Behrman RE (eds.). Nelson textbook of Pediatrics. 20 $0^{\text {th }}$ ed. New Delhi: Elsevier; 2016. p. 2586-92.

25. Andreoli SP. Acute renal failure in newborn, Semin Perinatol 2004;28:112-23

26. Sidhu G, Beyene J, Rosenblum ND. Outcome of isolated antenatal hydronephrosis: A systemic review and metaanalysis. Pediatr Nephrol. 2006;21: 218

27. Bagga A, Gulati A. Disease of the Newborn. In: Srivastava RN, Bagga A (eds.). Pediatric Nephrology. $6^{\text {th }}$ ed. New Delhi: Jaypee Brothers Medical Publishers (p) Ltd.; 2016. p. 532-560.

28. Agarwal S. Urethral valves. BJU Int. 1999; 84:570-8.

29. Chevalier RL. Perinatal bstructive nephropathy. Seminperinatol. 2004; 28:124-31.

30. Agarwal S. Urethral valves. BJU Int.1999; 84: 570-8.

31. Warady BA, Alexander SR, Watkins S, Kohaut E, Hermon WE. Optimal care of the pediatric end stage renal disease patient on dialysis. Am J Kidney Dis. 1999; 33:567-83.

32. Khan SZ, Fahim F, Mansoor K. Obstructive uropathy: causes and outcome in pediatric patient. JPMI. 2012;26:176-182. 